\title{
Professionalism: social media outreach
}

$\mathrm{P}$ atients who hack through the untamed wilds of the Internet in pursuit of medical information may return from the hunt with some rather foul prey. Funny how a few keystrokes can turn a harmless rash into a harbinger of doom. Of course, patients could be forgiven for occasionally gravitating toward bad medical information online, considering the gargantuan ocean of data out there. That's why some doctors feel it is one of their professional duties to harness the power of social media to steer patients toward legitimate sources of useful medical information.

"That's part of our professionalism, educating the population and sharing good information," says Dr. Katherine Chretien, chief of the hospitalist section at the Washington DC VA [Veterans Affairs] Medical Center and an associate professor of medicine at George Washington University in Washington, DC. "It's tremendously exciting to see the possibilities of social media for communicating in new ways and providing new ways of reaching patients, but doctors need to be careful and make sure they are acting professional online because their digital reputation is going to stay with them forever."

Few physicians have examined the potential of social media websites such as Facebook, Twitter and LinkedIn - to enhance the medical profession as closely as Chretien. "A compelling case for quality improvement through better communication via social media can be made, and medical professionalism encompasses a commitment to quality improvement," she and colleagues once wrote in a paper, "Online professionalism and the mirror of social media," noting that some have argued modern physicians are obligated to maintain an accessible and useful online presence ( $J$ Gen Intern Med 2010;25:1227-9).

Chretien, who is herself an active user of social media, has also explored the pros and cons of accepting a "friend" request from a patient on Face-

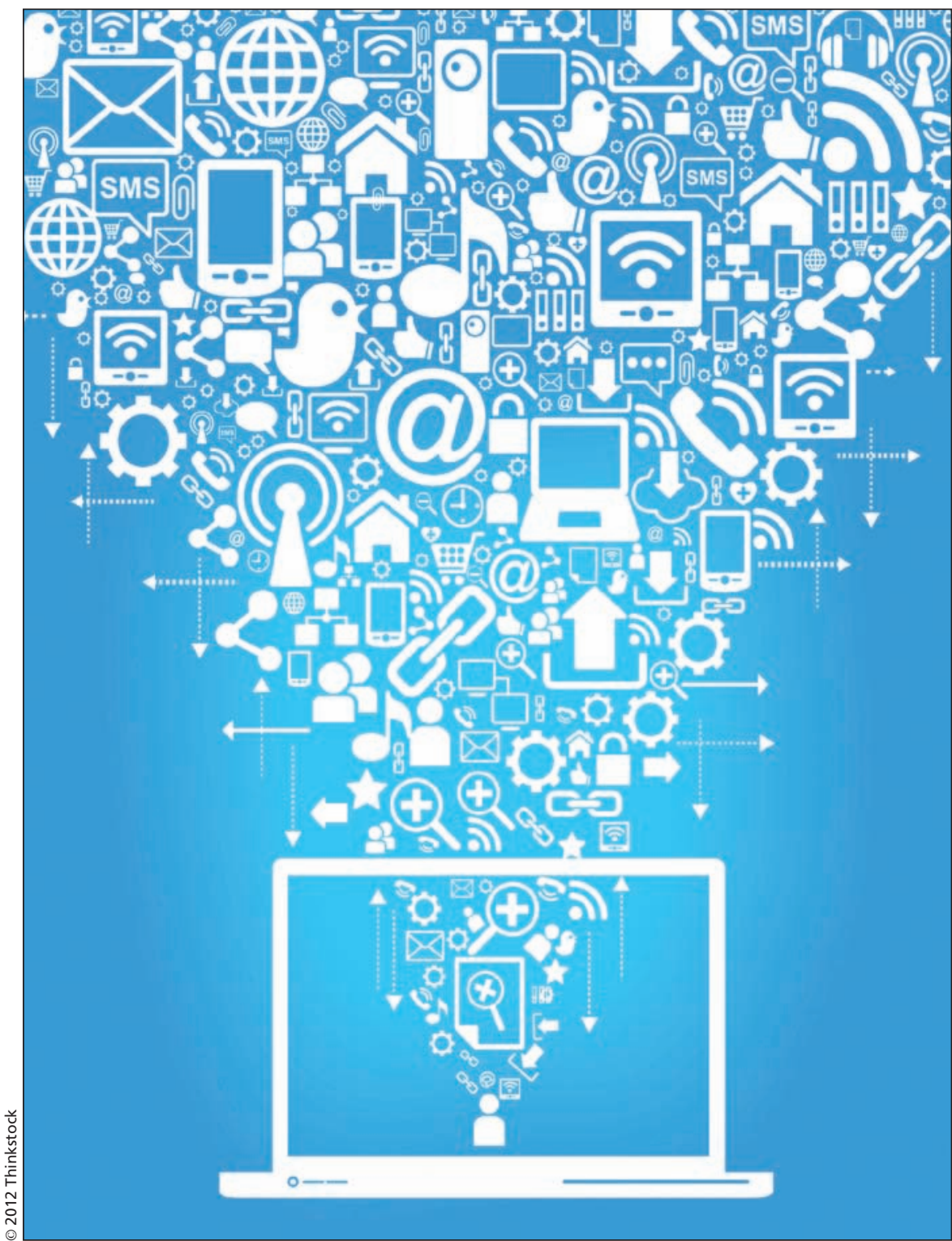

Medical professionalism encompasses quality improvement, and some physicians argue that social media tools could improve the quality of patient care through better communication.

book (Am Fam Physician 2011;84:105$8)$. Accepting such requests would allow physicians to learn more about their patients, possibly leading to better management of their medical problems. Patients may also be offended if physicians refuse "friend" requests, which could affect their therapeutic relationships. Still, it is perhaps more appropriate to connect directly with patients on a professional social networking site, such as LinkedIn, rather than on a personal Facebook page.

"Although some shared banter on mutual interests can help build rapport between physicians and patients, excessive self-disclosure is unlikely to be helpful in the clinical setting, and could lead to boundary violations, sexual or otherwise," wrote Chretien. "Also, what if you discover a photograph of your patient, whom you just 
referred for gastric bypass surgery, competing in a doughnut-eating contest? Would it be appropriate to bring that up at an office visit?"

From the patient's perspective, however, it is easy to understand the temptation to reach out to physicians via social media, says Chretien. "There may be a feeling for some that we have lost the relationship that physicians had with patients in the past, when we knew them well and spent more time with them. Perhaps this is one way they could communicate more and build more trust. It could help them see the human side of their physicians."

Social media can also be an effective tool for physicians to generate and disseminate their own medical information, says Dr. Kevin Pho, who practises internal medicine in Nashua, New Hampshire, and serves as "social media's leading physician voice" on his popular website (kevinmd.com). "Physicians can guide patients to reputable sources or become reputable sources themselves. A doctor can get on a blog and write an editorial. Providing that type of education is one of the biggest advantages that social media brings to medicine."

But what about blogs written by patients? Should doctors be compelled to read them? It might prove useful in certain cases - a psychiatrist could learn of a patient's intention to commit suicide or harm others, for example. On the other hand, expecting busy physicians to wade through the online writings of all their patients may be unreasonable.

"It's a real dilemma. In some cases, it might seem irresponsible not to follow the blog. In other cases, it would be just logistically impossible," says Dr. David Brendel, a psychiatrist practising in the area of Boston, Massachusetts, and a sought-after educator on matters of medical ethics and professionalism (drdavidbrendel.com). "The more patients who have blogs or are using Twitter and putting information about themselves into the public sphere, the question is: What is appropriate and necessary for physicians to know?" - Roger Collier, CMAJ

CMAJ 2012. DOI:10.1503/cmaj.109-4207

Editor's note: Fifth in a multipart series on medical professionalism.

Part I: The "good doctor" discussion (www.cmaj.ca/lookup/doi/10.1503/cmaj .109-4200).

Part II: What is it? (www.cmaj.ca /lookup/doi/10.1503/cmaj.109-4211).

Part III: The historical contract (www.cmaj.ca/lookup/doi/10.1503/cmaj $.109-4230)$.

Part IV: Can it be taught? (www.cmaj .ca/lookup/doi/10.1503/cmaj.109-4232). 